\title{
Synthesis and biological evaluation of new naphthoquinones derivatives by catalytic oxidation
}

\author{
El-Mahdi Ourhzif ${ }^{1,2,3}$, Caroline Decombat ${ }^{4}$, Florence Caldefie-Chezet ${ }^{4}$, Pierre Chalard ${ }^{1}$, Yves \\ Troin ${ }^{1, *}$, Mostafa Khouili ${ }^{3}$ and Mohamed Akssira ${ }^{2, *}$ \\ 1 Université Clermont Auvergne, CNRS, SIGMA Clermont, ICCF, F-63000 Clermont-Ferrand, France \\ 2 Université Hassan II Casablanca, FST, Laboratoire de Chimie Physique et Chimie Bio organique BP \\ 146,28800 Mohammedia, Maroc \\ 3 Université Sultan Moulay Slimane, FST, Laboratoire de Chimie Organique et Analytique, BP 523 Beni- \\ Mellal, Maroc \\ 4 Université Clermont Auvergne, INRA, Unité de Nutrition Humaine, CRNH Auvergne, F-63000 Clermont- \\ Ferrand, France. \\ * Correspondence: akssira.m@gmail.com
}

The catalytic utilization of hypervalent iodine reagents, largely in consideration of economical and environmental viewpoints, is a most attractive strategy due to their unique features as extremely useful oxidants, with mild, safe, and environmentally friendly characteristics. Oxidation reactions constitute of a number of important transformations in organic synthesis. They are widely in the productions of a variety of fine chemicals including pharmaceuticals, natural products, and their intermediates.[1] As oxidants, hypervalent iodine reagents have recently received much attention due to their low toxicity, mild reactivity, ready availability, high stability, easy handling, etc.[2-6] For examples, phenyliodine(III) diacetate (PIDA) and phenyliodine(III) bis (trifluoroacetate) (PIFA)induced oxidations of phenols and related reactions have been applied to many total syntheses of biologically important natural products and their pivotal intermediates.[7-9] This study reports a new synthetic methodology that was optimized to prepare new naphthoquinones derivatives 13-16 via catalytic oxidation. The latter were prepared in 5-6 steps from naphtol 1 in overall yields (11-34\%). The synthetic pathway of these new analogs is depicted in Scheme. Hypervalent iodine is the most common method to oxidize methoxy phenols or methoxy naphthols in naphtoquinones. On the one hand, treatment of $\mathbf{1}$ with phenyliodonium diacetate) (PIDA) in a mixture of acetonitrile/methanol (1/1) led efficiently to naphthol 2 (76\% yield) which after methylation furnished compound 3 in excellent yield $(94 \%)$. On the other hand, the oxidation of phenol into quinone monoacetal was frequently observed in the alcoholic solvent. Hence, compound $\mathbf{1}$ was treated with phenyliodonium bis(trifluoroacetate) (PIFA) in methanol (2 eq.) to give quinone monoacetal 4 in $85 \%$ yield. Nucleophilic substitution of sodium methylate furnished naphthol 5 (40\% yield). The conversion of naphthols to the corresponding naphthoquinones 13-16 were reacted with either cerium (IV) ammonium nitrate (CAN) or phenyliodonium diacetate (PIDA), the results were disappointing. Therefore, the experimental conditions were optimized by varying the time of reaction and solvent ratio.

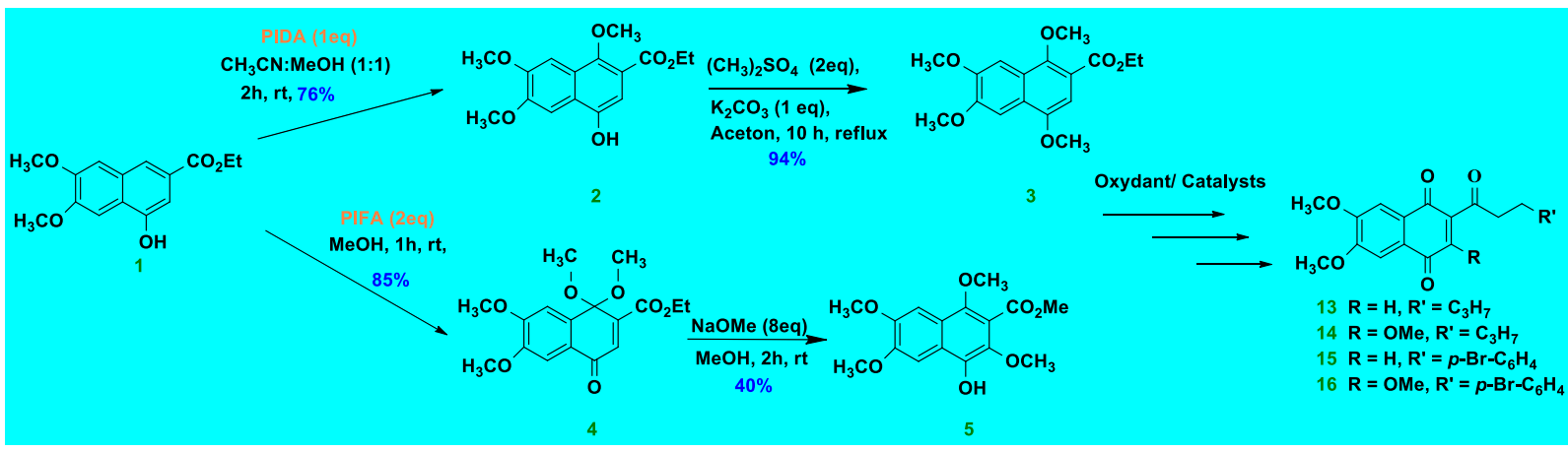

Scheme1. The synthetic pathway of naphthoquinones derivatives via catalytic oxidation. 
Keywords: Naphthoquinones; naphthols; phenyliodine(III) diacetate (PIDA), phenyliodine(III) bis(trifluoroacetate) (PIFA), catalytic oxydation; cerium (IV) ammonium nitrate (CAN)

1. Hoelderich, W. F., Kollmer, F. Oxidation reactions in the synthesis of fine and intermediate chemicals using environmentally benign oxidants and the right reactor system. Pure Appl. Chem. 2000, $72,1273$.

2. Zhdankin, V.V.; Stang, P.J. Recent Developments in the Chemistry of Polyvalent Iodine Compounds. Chem. Rev. 2002, 102, 2523-2584.

3. Tohma, H. ; Kita, Y. Hypervalent Iodine Reagents for the Oxidation of Alcohols and Their Application to Complex Molecule Synthesis. Adv. Synth. Catal. 2004, 346, 111.

4. Moriarty, R. M. Organohypervalent Iodine: Development, Applications, and Future Directions. J. Org. Chem, 2005, 70, 2893-2903.

5. Wirth, T. Hypervalent Iodine Chemistry in Synthesis: Scope and New Directions. Angew. Chem. Int. Ed. 2005, 44, 3656.

6. Ochiai, M. Stoichiometric and catalytic oxidations with hypervalent organo- $\lambda 3$-iodanes. Chem. Rec. $2007,7,12$.

7. Pouységu, L.; Deffieux, D.; Quideau, S. Hypervalent iodine-mediated phenol dearomatization in natural product synthesis. Tetrahedron. 2010, 66, 2235-2261.

8. Moriarty, R.; Prakash, O. Oxidation of phenolic compounds with organohypervalent iodine reagents in Organic Reactions. Wiley New York, 2001, 57, 327-415.

9. Ladziata, U.; Zhdankin, V.V. Hypervalent iodine(V) reagents in organic synthesis. ARKIVOC, 2006, $9,26-58$.

Publisher's Note: MDPI stays neutral with regard to jurisdictional claims in published maps and institutional affiliations.

(C) 2020 by the authors. Submitted for possible open access publication under the terms and conditions of the Creative Commons Attribution (CC BY) license (http://creativecommons.org/licenses/by/4.0/). 